replacement therapy wich significantly increased the survival of these patients.

\section{PO-0044 A REVIEW OF THE CLINICAL PRACTICE OF PAEDIATRICIANS WITH EXPERTISE IN CARDIOLOGY (PECS) IN THE UK}

${ }^{1} \mathrm{Y}$ Singh, ${ }^{2} \mathrm{H}$ Andrews, ${ }^{1} \mathrm{~W}$ Kelsall. ${ }^{1}$ Addenbrooke's Hospital, Cambridge University Hospitals NHS Foundation Trust, Cambridge, UK; ${ }^{2}$ College of Medical and Dental Sciences, University of Birmingham, Birmingham, UK

\subsection{6/archdischild-2014-307384.719}

Background Recently there have been significant developments in PEC training and service aims including the recognition of Paediatrician with Expertise in Cardiology Special Interest Group (PECSIG) by the RCPCH and British Congenital Cardiac Association (BCCA), the creation of an agreed SPIN-module training curriculum for PECs and the development of PEC-specific service standards by the BCCA.

Aim To find out which clinical services are provided by PECs and to determine the extent of variability in their clinical practice.

Methods An internet-based questionnaire was sent out via PECSIG and NICHe (Neonatologists with Interest in Cardiology and Haemodynamics) contact databases and an NHS directory. Nonresponders were followed up via telephone.

Results The response rate was 72\% (129 of 179 hospitals). PECs carried out echocardiography in all hospitals in which they were employed (69\%). Support for this service was provided by echo-technicians in $36 \%$ of hospitals and by neonatologists in $27 \%$.

PEC-led outpatient clinics were held at least fortnightly in $66 \%$ of hospitals. The mode duration of appointment for a new patient was $30 \mathrm{~min}$ (range $<20 \mathrm{~min}$ to $>45 \mathrm{~min}$ ) while for the follow-up appointment the mode was $20 \mathrm{~min}$ (range $<20 \mathrm{~min}$ to $>45 \mathrm{~min}$ ).

Telemedicine facilities were established in only $45 \%$ centres, where sharing echocardiogram images via PACS was used most commonly.

Conclusion There remains significant variation in PEC services especially regarding the frequency of clinics, the duration of appointments and telemedicine utilisation. It was reassuring to see a relatively high number of hospitals offering PEC-led echocardiography and other PEC service provision.

\begin{tabular}{lc} 
Abstract PO-0044 Table 1 & PEC service provision \\
\hline Type of service & $\begin{array}{l}\text { Percentage of centres providing } \\
\text { service }\end{array}$ \\
\hline Paediatric echocardiography & $87 \%$ \\
12-lead ECG & $98 \%$ \\
24-hour Holter ECG & $91 \%$ \\
24-hour ambulatory BP monitoring & $74 \%$ \\
Long term external cardiac monitoring (e.g. cardiac \\
memo) & $56 \%$ \\
Exercise testing & $47 \%$ \\
Other services* & $4 \%$ \\
* a handful offered TILT test and fetal echocardiography facilities \\
\hline
\end{tabular}

\section{P0-0045 A REVIEW OF THE AVAILABILITY OF PEC (PAEDIATRICIAN WITH EXPERTISE IN CARDIOLOGY) SERVICES IN THE UK}

${ }^{1} \mathrm{H}$ Andrews, ${ }^{2} \mathrm{~W}$ Kelsall, ${ }^{2} \underline{Y}$ Singh. ${ }^{1}$ College of Medical and Dental Sciences, University of Birmingham, Birmingham, UK; ${ }^{2}$ Addenbrooke's Hospital, Cambridge University Hospitals NHS Foundation Trust, Cambridge, UK

\subsection{6/archdischild-2014-307384.720}

Background A national survey completed in 2008 reported that PEC services were available in only $35 \%$ of non-specialist paediatric cardiology hospitals in the UK. In 2012, the NHS Specialised Services Commission recommended that there should be an increased level of PEC services in all hospitals as part of their 'Safe and Sustainable' review.

Aim To determine the availability of PEC services in the UK.

Methods An internet-based questionnaire was sent out via PECSIG and NICHe (Neonatologists with Interest in Cardiology and Haemodynamics) contact databases and an NHS directory. Nonresponders were followed up via telephone.

Results The response rate was 72\% (129 of 179 hospitals). Of these hospitals, 69\% had established PEC services with at least 1 PEC employed and 19\% had two or more PECs. In all centres echocardiograms were performed by either PEC consultants or specialist paediatricians, with support from echo-technicians in $36 \%$.

Local PEC-led outpatient clinics ran at least fortnightly in two-thirds (66\%) of hospitals, whilst $63 \%$ of hospitals held outreach clinics with a paediatric cardiologist from a specialist centre at least monthly. However, 12 of the hospitals without any PEC services reported that they never held out-reach clinics either.

Conclusion There has been a substantial increase in PEC availability in non-specialist paediatric cardiology hospitals $(69 \%$ as compared to $35 \%$ in 2008) but still $31 \%$ had no established PEC services. In most but not all hospitals without PEC services, support is offered by tertiary-centres for paediatric cardiology through out-reach clinics.

\section{PO-0046 CLINICAL AND ECHOCARDIOGRAPHIC EFFECTS OF HYPOCALCEMIA SECONDARY TO SEVERE VITAMIN D DEFICIENCY (VDD) AND EFFECT OF TREATMENT}

A Soliman, S Saeed, A Khellah. Pediatrics, Hamad Medical Centre, Doha, Qatar

\subsection{6/archdischild-2014-307384.721}

Introduction Hypocalcemia (HC), without an underlying myocardial disease, is a relatively uncommon but reversible cause of congestive heart failure.

Objective We studied the cardiac functions (heart rate, blood pressure, ECG and Echocardiographic parameters (Fractional shortening (FR), left ventricular end diastolic diameter (LVEDD) of 14 children who presented with hypocalcaemia due to VDD before and 2-4 weeks after treatment with an IM dose of vita$\min \mathrm{D} 3$ (VD) $(10,000 \mathrm{IU} / \mathrm{kg})$.

Results Correction of HC and VDD was associated with marked improvement of the LVEDDSDS $(3.2 \pm 4.4$ to $1.1 \pm 2.8)$ and slowing of the heart rate (from $101 \pm 34$ to $94.7 \pm 30 / \mathrm{min}$ ). The FS and QTc did not change. The LVEDDSDS was negatively correlated with serum calcium level $(r=-0.46, p=0.03)$ and PTH concentrations $(r=0.44, p=0.032)$ but not with 25OHD level $(r=-0.2, p=0.2)$. 